Published by Al-Nahrain College of Medicine P-ISSN 1681-6579

E-ISSN 2224-4719

Email: iraqijms@colmed-alnahrain.edu.iq

http://www.colmed-alnahrain.edu.iq

http://www.iraqijms.net

Iraqi JMS 2020; Vol. 18(2)

\title{
Role of Forced Expiratory Volume in Third second (FEV3) as An Alternative to Forced Vital Capacity (FVC) in Assessing Bronchodilator Response in Patients with Chronic Obstructive Airway Diseases
}

\author{
Alaa Y. Jizar ${ }^{1} M S C$, Zeinab H. Hashim ${ }^{2}$ PhD, Ahmed H. Jasim ${ }^{3}$ FIBMS \\ ${ }^{1}$ Merjan Teaching Hospital, Babylon, Iraq, ${ }^{2}$ Dept. of Physiology, College of Medicine, Al-Nahrain University, Baghdad, \\ Iraq, ${ }^{3}$ Dept. of Medicine, College of Medicine, University of Babylon, Babylon, Iraq
}

\begin{abstract} differentiate asthma from COPD. diseases. defect on spirometer. assessing bronchodilator response.

Citation

List of abbreviations: ATS = American Thoracic Society. ERS $=$ European Respiratory Society, FEV1 = Forced expiratory volume in first second, FEV3 = Forced expiratory volume in third second, FVC = Forced vital capacity, FEV1/FVC = Ratio of volumes (actual), FEV1/FVC\% = Ratio of predicted values, FEV1/ FEV3 = Ratio of volumes (actual), FEV1/FEV3\% = Ratio of predicted values
\end{abstract}

Background Spirometry is a physiological procedure used as a diagnostic tool for disease diagnosis; e.g. obstructive pulmonary diseases such as asthma or chronic obstructive pulmonary disease (COPD). The bronchodilator test is a method of measuring lung capacity changes following inhalation of a short-acting bronchodilator drug that dilates the airway, this test helps to diagnose, evaluate and

Objective To evaluate the role of forced expiratory volume in third second (FEV3) as an alternative for forced vital capacity (FVC) in assessing bronchodilator response in patients with chronic obstructive airway

Methods The study a case-control, comparative study done from November 2018 to November 2019. The cases involved divided into 2 groups; patients group included (80) patients with chronic obstructed pulmonary diseases (asthma and COPD) and control group included (160) apparently healthy peoples aged and sex matched. Lung function was measured using a standard protocol and electronic table spirometry. Bronchodilator test was done for each patient with chronic obstructed

Results There was no significant difference between (FVC), FVC\% and (FEV3), FEV3\% respectively before bronchodilator and there was no significant difference after bronchodilator in patients. There was no significant difference between FEV1/FVC, FEV1/FVC \% and FEV1/ FEV3, FEV1/FEV3\% respectively before bronchodilator and there was no significant difference after bronchodilator in patients.

Conclusion FEV3 can be used as an alternative to FVC in patients with chronic obstructive airway diseases for

Keywords Spirometry, Bronchodilator test, FVC\%, FEV3\%, FEV1/FVC\%, FEV1/FEV3\%

Jizar AY, Hashim ZH, Jasim AH. Role of forced expiratory volume in third second (FEV3) as an alternative to forced vital capacity (FVC) in assessing bronchodilator response in patients with chronic obstructive airway diseases. Iraqi JMS. 2020; 18(2): 94-100. doi: 10.22578/IJMS.18.2.2

\section{Introduction}

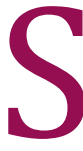
pirometry is a physiological procedure for determining the functional aspects of the lungs using an objective measure by calculating how much air a patient can inhale and exhale to the limit ${ }^{(1)}$. Spirometry is used as a diagnostic tool for disease diagnosis e.g. 
obstructive pulmonary diseases such as asthma or chronic obstructive pulmonary disease (COPD) and restrictive lung conditions such as interstitial pneumonia (2).

The principal indices of spirometry are: (a) Forced Vital Capacity (FVC), (b) Forced Expiratory Volume in the first second (FEV1), (C) FEV1/FVC. The presence of FEV1 $<80 \%$ of the expected value in conjunction with FEV1/FVC $<70 \%$ indicates the presence of airway obstruction ${ }^{(3)}$. The bronchodilator test is a method of measuring lung capacity changes following inhalation of a short-acting bronchodilator drug that dilates the airway, this test helps to diagnose, evaluate and differentiate asthma and COPD by measuring reversibility brought by the bronchodilator drug (4). Generally, a positive response is defined as a rise of $\geq 12 \%$ and $\geq 200 \mathrm{~mL}$ in an absolute level of FEV1 and/or FVC compared with baseline (2). If the response to the bronchodilator is positive it usually suggests asthma. It is because the rise in post-inhalation flow rate and volume in asthma patients is greater than in COPD patients (5). Other spirometry indices are forced third-second expiratory volume (FEV3) as the second most commonly studied dependable parameter as an alternative to FVC as they are easier because patients are not required to perform maximum end-expiration ${ }^{(6)}$. FEV3 are suitable alternatives for FVC in the spirometric analysis of bronchial asthma. The assumption was based on the lack of significant differences in the means when the absolute values of FEV3 were matched with FVC in asthmatic patients. This significant in suggestions all advantages of FEV3 over FVC in asthmatic patients (7). Sometimes, FVC maneuvers are correctly performed, and the patients can blow greater than 3 seconds but cannot reach the end-oftest criteria ( 6 seconds in duration or a plateau in the volume-time curve) after trying the analysis several times. The FEV 3 has been proposed as an approximate surrogate for the FVC (8).
Asthma is a chronic airway inflammatory condition characterized by cellular penetration into the airways and a related increase in sensitivity and reaction to agents that cause bronchial contraction (airway hyper-responseAHR) and exposure to allergens (early and late asthmatic responses) ${ }^{(9)}$. COPD is the term for the set of conditions, including chronic bronchitis and emphysema, that block air flow in the bronchi and trachea. More precisely, international organizations have described COPD as a disorder characterized by airflow obstruction that is not entirely reversible ${ }^{(10)}$.

The aim of this study was to evaluate the role of FEV3 as an alternative for FVC in assessing bronchodilator response in patients with chronic obstructive airway diseases.

\section{Methods \\ Subjects}

The study a case-control, comparative study conducted for chronic obstructed air way diseases patients (asthma and COPD). Data were collected in Spirometric Unit in Merjan Teaching Hospital in Babylon city at a duration from November 2018 to November 2019. The study approved by the Institutional Review Board (IRB) of the College of Medicine, AlNahrain University and informed consents were obtained from all the participants.

The cases divided into 2 groups; patients group included (80) patients with chronic obstructed lung diseases; (31) male and (49) female whom mean age was (51) years and they were referred to spirometry unit. They enrolled in the study with FEV1/FVC $<70$ and FEV1\% $<80 \%$ of the predicted. Control group included (160) apparently healthy peoples aged and sex matched, mean age was (45) years. Females were (100), males were (60) in number.

\section{Materials}

A- Spirometry: Lung function was measured using a standard protocol and electronic table spirometry (SpirolabIII, Italy).

B- Nebulizer: Bronchodilator test is recommended to evaluate airway responsiveness. Bronchial responsiveness 
was measured by changes in spirometric parameters after the inhaling $(2.5 \mathrm{mg})$ of short-acting $\beta 2$ - agonists (salbutamol). Bronchodilator test was done for each patient with chronic obstructed defect on spirometer. For each patient with obstructed deficiency, post-bronchodilator spirometry was performed 20 minutes after inhalation of salbutamol.

\section{Statistical analysis}

Statistical analysis was performed with SPSS V22. (statistical package for social sciences) for data comparison and also Excel 2010 programs. Data analysis was done using paired t-test.
Data were expressed as mean \pm standard deviation (SD) and the values were considered statistically significant when $p$-value $(<0.05)$.

\section{Results}

From 80 Patients enrolled in the study; 55 (68.8\%) showed positive bronchodilator response (asthma) and 25 (31.3\%) showed negative response (COPD).

There was significant difference $(p<0.05)$ between patients and control regarding all spirometric parameters and all parameters are lower than that of normal subjects (Table 1).

Table 1. Comparisons of means of spirometric parameters between patients and control group

\begin{tabular}{cccccc}
\hline \multirow{2}{*}{ Parameters } & \multicolumn{2}{c}{ Patients } & \multicolumn{2}{c}{ Control } & \multirow{2}{*}{ P value } \\
\hline FEV1\% & 53.69 & 18.29 & 94.21 & 9.89 & $<0.001$ \\
FVC\% & 66.54 & 18.46 & 91.65 & 9.82 & $<0.001$ \\
FEV3\% & 68.48 & 19.43 & 96.13 & 12.80 & $<0.001$ \\
FEV1/FVC\% & 79.16 & 12.39 & 102.27 & 8.23 & $<0.001$ \\
FEV1/FEV3\% & 77.28 & 11.50 & 98.01 & 10.24 & $<0.001$ \\
FEV1/FVC & 63.00 & 11.57 & 102.68 & 8.50 & $<0.001$ \\
FEV1/FEV3 & 68.37 & 10.87 & 95.49 & 6.92 & $<0.001$ \\
FVC (L) & 2.50 & 1.05 & 3.62 & 0.82 & $<0.001$ \\
FEV1 (L) & 1.61 & 0.74 & 3.11 & 0.72 & $<0.001$ \\
FEV3 (L) & 2.29 & 1.00 & 3.60 & 0.83 & $<0.001$ \\
\hline
\end{tabular}

There was significant difference $(p<0.05)$ in FEV1\%, FEV1(L), FVC\%, FEV3\% before and after nebulizer. Other parameters showed no significant difference $(p>0.05)$ pre- and postnebulizer (Table 2).

There was no significant difference $(p>0.05)$ between FVC\% and FEV3\% before bronchodilator and there was no significant difference ( $p>0.05)$ between FVC\% and FEV3\% after bronchodilator (Table 3).

There was no significant difference $(p>0.05)$ between FVC (L) and FEV3 (L) before bronchodilator and there was no significant difference $(p>0.05)$ between FVC (L) and FEV3 (L) after bronchodilator (Table 4).

There was no significant difference $(p>0.05)$ between FEV1/FVC\% andFEV1/FEV3\% before bronchodilator and there was no significant difference $(p>0.05)$ between FEV1/FVC\% and FEV1/FEV3\% after bronchodilator (Table 5).

There was no significant difference $(p>0.05)$ between FEV1/FVC and FEV1/FEV3 before bronchodilator and there was no significant difference $(p>0.05)$ between FEV1/FVC and FEV1/FEV3 after bronchodilator (Table 6). 
Table 2. Baseline and Post-bronchodilator values of different spirometric parameters

\begin{tabular}{|c|c|c|c|c|}
\hline \multicolumn{2}{|c|}{ Parameters } & \multirow{2}{*}{$\begin{array}{c}\text { Mean } \\
53.69\end{array}$} & \multirow{2}{*}{$\frac{\text { SD }}{18.29}$} & \multirow{3}{*}{$\begin{array}{l}\mathbf{P} \text { value } \\
<0.001\end{array}$} \\
\hline \multirow{2}{*}{ FEV1\% } & Pre* & & & \\
\hline & Post** & 94.16 & 10.38 & \\
\hline \multirow{2}{*}{ FVC\% } & Pre & 66.54 & 18.46 & \multirow{2}{*}{$<0.001$} \\
\hline & Post & 91.01 & 9.59 & \\
\hline \multirow{2}{*}{ FEV1/FVC\% } & Pre & 79.29 & 12.4 & \multirow{2}{*}{0.085} \\
\hline & Post & 82.83 & 13.41 & \\
\hline \multirow{2}{*}{ FEV3\% } & Pre & 68.83 & 19.71 & \multirow{2}{*}{$<0.001$} \\
\hline & Post & 94.43 & 18.96 & \\
\hline \multirow{2}{*}{ FEV1/FEV3\% } & Pre & 77.31 & 11.18 & \multirow{2}{*}{0.095} \\
\hline & Post & 80.45 & 12.43 & \\
\hline \multirow{2}{*}{ FVC (L) } & Pre & 2.5 & 1.05 & \multirow{2}{*}{0.114} \\
\hline & Post & 2.76 & 1.02 & \\
\hline \multirow{2}{*}{ FEV1 (L) } & Pre & 1.61 & 0.74 & \multirow{2}{*}{0.043} \\
\hline & Post & 1.86 & 0.82 & \\
\hline \multirow{2}{*}{ FEV3 (L) } & Pre & 2.29 & 1.0 & \multirow{2}{*}{0.061} \\
\hline & Post & 2.59 & 1.02 & \\
\hline \multirow{2}{*}{ FEV1/FVC } & Pre & 63.04 & 11.57 & \multirow{2}{*}{0.081} \\
\hline & Post & 66.14 & 10.75 & \\
\hline \multirow{2}{*}{ FEV1/FEV3 } & Pre & 68.4 & 10.88 & \multirow{2}{*}{0.052} \\
\hline & Post & 71.48 & 8.99 & \\
\hline
\end{tabular}

*Pre: before nebulizer, ${ }^{* *}$ post: after nebulizer

Table 3. Comparison between FVC \% and FEV3 \% before \& after bronchodilation

\begin{tabular}{cccccc}
\hline & \multicolumn{2}{c}{ FVC\% } & \multicolumn{2}{c}{ FEV3\% } & \multirow{2}{*}{ P value } \\
\hline Mean & SD & Mean & SD & \\
\hline Pre & 66.54 & 18.46 & 68.83 & 19.71 & 0.190 \\
Post & 91.01 & 9.60 & 94.43 & 18.96 & 0.086 \\
\hline
\end{tabular}

*Pre: before nebulizer, **post: after nebulizer

Table 4. Comparison between FVC (L) and FEV3 (L) before \& after bronchodilation

\begin{tabular}{cccccc}
\hline & \multicolumn{2}{c}{ FVC (L) } & \multicolumn{2}{c}{ FEV3 (L) } & \multirow{2}{*}{ P value } \\
& Mean & SD & Mean & SD & \\
\hline Pre & 2.50 & 1.05 & 2.29 & 1.00 & $\mathbf{0 . 8 7 6}$ \\
Post & 2.76 & 1.02 & 2.59 & 1.02 & $\mathbf{0 . 7 9 4}$ \\
\hline
\end{tabular}

*Pre: before nebulizer, ${ }^{* *}$ post: after nebulizer 
Table 5. Comparison between FEV1/FVC\% and FEV1/FEV3\% before \& after bronchodilation

\begin{tabular}{cccccc}
\hline & \multicolumn{2}{c}{ FEV1/FVC\% } & \multicolumn{2}{c}{ FEV1/FEV3\% } & \multirow{2}{*}{ P value } \\
& Mean & SD & Mean & SD & \\
\hline Pre & 79.29 & 12.40 & 77.31 & 11.18 & $\mathbf{0 . 0 9 7}$ \\
Post & 82.83 & 13.41 & 80.45 & 12.43 & $\mathbf{0 . 1 2 3}$ \\
\hline
\end{tabular}

*Pre: before nebulizer, ${ }^{* *}$ post: after nebulizer

Table 6. Comparisons between FEV1/FVC (L) and FEV1/FEV3 (L) before \& after bronchodilation

\begin{tabular}{cccccc}
\hline & \multicolumn{2}{c}{ FEV1/FVC (L) } & \multicolumn{2}{c}{ FEV1/FEV3 (L) } & \multirow{2}{*}{ P value } \\
& Mean & SD & Mean & SD & \\
\hline Pre & 63.04 & 11.58 & 68.40 & 10.88 & 0.074 \\
Post & 66.14 & 10.75 & 71.48 & 8.99 & 0.067 \\
\hline
\end{tabular}

*Pre: before nebulizer, ${ }^{* *}$ post: after nebulizer

\section{Discussion}

There were significant difference between patients and control regarding all spirometric parameters and all parameters are lower than that of normal subjects, this could be explained as follows; Cohen et al. (2007) proposed that a reduction in FVC suggests small airway closing and gas trapping (11), Siatkowska et al. (2010) \& Al-Dhahir et al. (2012) mentioned that the presence of FEV1 $<80 \%$ of the expected value in conjunction with FEV1/FVC $<70 \%$ indicates the presence of minimal air flow ${ }^{(12,3)}$, Kitaguchi et al. (2012) mentioned that spirometric principle for airflow limitation is FEV1/FVC ratio $<70 \%$ regarding the GOLD guidelines, moreover, Patel et al. (2019) reported that chronic inflammation and airway remodeling of COPD and asthma can also cause persistent airflow limitations ${ }^{(13,14)}$, Lutfi (2011) found in his study that all the spirometric measurements studied in asthma patients were significantly lower than the control group, indicating that patients had significant airway obstruction ${ }^{(7)}$.

There was significant difference in FEV1\%, FEV (L), FVC\% and FEV3\% before and after nebulizer. Other parameters showed no significant difference pre and post nebulizer administration. These results agree with the followings; Albert et al. (2013) who stated that reversibility was specified by the $=$ American Thoracic Society (ATS) and European Respiratory Society (ERS) criterion of $\geq 12 \%$ and $\geq 200 \mathrm{ml}$ of pre-bronchodilator FEV1 or the FEV1\% increase ${ }^{(15)}$, Quanjer et al. (2016) found that FVC in detecting bronchial reversibility in COPD patients was reported to be more sensitive than FEV1 ${ }^{(16)}$. Pan et al. (2019) said that his results reported that FEV3 and FVC are sensitive indicators of bronchodilation in extreme airway obstruction, while FEV1 is more sensitive in mild ventilator dysfunction bronchodilation assessment (17). While Cazzola et al. (2008) had another opinion, they mentioned that FEV1 is the most commonly used pulmonary measure and the clinical studies have shown that changes in FEV1 before and after treatment are not sufficiently enough to indicate the influence of bronchodilators in patients with extreme airflow obstruction, in particular the elderly ${ }^{(18)}$. Mehrparvar et al. (2014) mentioned that in a large number of cases, FVC decreased after administration of bronchodilator ${ }^{(6)}$. which was in agreement with the findings of Kainu (2009) (19).

The other parameters show no significant difference pre and post nebulizer, which could be due to different type of obstructions (COPD) and different degrees included in the study ${ }^{(20)}$. 
Other cause could be due to the increase in both FEV1and FVC (FEV1/FVC\%), FEV1 and FEV3 (FEV1/FEV3\%).

In this study there was no significant difference between FVC \%, FVC (L) and FEV3\%, FEV3 (L) respectively per nebulizer and there was no significant difference post nebulizer with bronchodilators. These results agree with the followings: Pellegrino et al. (2005) stated that FEV3 percent is by far the most commonly used parameter for airway obstruction, bronchoconstriction or bronchodilation assessments (21), Mehrparvar et al. (2014) found in his study that FEV3 change was significantly associated with FVC change post bronchodilators and can be used as a $n$ alternative for FVC in bronchodilator response assessment. bronchodilator test was significant in these parameters (6). Pan et al. (2019) mentioned that his study presented that recent data on FEV3suggesting its clinical applicability for better analysis of reversibility assessment, especially in severely impaired patients who enable blow for $\geq 6$ seconds even after their best effort (18). While Kainu (2008) proposed that based on the intersession repeatability, a limitation for significant change in FEV3 was recommended for forced expiratory time during bronchodilator test ${ }^{(19)}$.

There was no significant difference in FEV1/FVC\%, and FEV1/FVC and FEV1/FEV3\%, FEV1/FEV3 respectively before nebulizer and no significant difference also after administration of bronchodilator. These results agree with the followings: Allen et al. (2008) found that FEV1/FEV $3 \%<80 \%$ can be used to recognize patients with airflow obstruction if they were incapable to perform FVC maneuver (22), Lutfi, (2011) mentioned that the data of his study showed that the level of FEV1/FEV3\% of $<80 \%$ corresponding a FEV1/FVC\% of $<70 \%$ (7), Mehrparvar et al. (2012) had different opinion he mentioned that FEV1/FEV3 unsuccessful to show satisfactory accuracy for the restrictive and obstructive lung diseases diagnosis, even though these parameters have not been assessed previously ${ }^{(23)}$.

This study concluded that FEV 3 can be used as an alternative to FVC in evaluating the response to bronchodilator in patients with chronic obstructive diseases; asthma and COPD, the conclusion was based on the absence of the significant differences in the means when the values of FEV3, FEV3 percent were matched with FVC, FVC percent before and after nebulizer.

\section{Acknowledgement}

Thanks, and regards to all staff members in Department of Physiology, College of Medicine, Al-Nahrain University, all staff in Respiratory Diseases Consultations and Spirometry Unit in Merjan Teaching Hospital in Babylon city.

\section{Author contribution}

Dr. Jizar conducted the study, collected the data and performed the statistical analysis and drafting the manuscript. Dr. Hashim and Dr. Jasim contributed in the designing, organization and finalization of manuscript.

\section{Conflict of interest}

There are no conflicts of interest.

Funding

Self-funded.

\section{References}

1. Sim YS, Lee JH, Lee WY, et al. Spirometry and bronchodilator test. Tuberc Respir Dis (Seoul). 2017; 80(2): 105-12. doi: 10.4046/trd.2017.80.2.105.

2. Miller MR, Hankinson J, Brusasco V, et al. Standardisation of spirometry. Eur Respir J. 2005; 26(2): 319-38. doi: 10.1183/09031936.05.00034805.

3. Al-Dhahir $H$, Baay $A$, Abbas $A H$. Pulmonary function tests abnormalities predictors in smoker patients. AlQadisiyah Med J. 2014; 10(17): 28-42.

4. Pruitt B. Spirometry and response to bronchodilator studies. J Asthma Allergy Educators. 2012; 3(2): 73-7. doi: $10.1177 / 2150129711434769$.

5. Soares AL, Pereira CA, Rodrigues SC. Spirometric changes in obstructive disease: after all, how much is significant? J Bras Pneumol. 2013; 39(1): 56-62. doi: 10.1590/s1806-37132013000100008.

6. Mehrparvar AH, Mirmohammadi SJ, Hashemi SH, et al. Bronchodilator response of FEV6 and FEV3 as surrogates of forced vital capacity. Tanaffos. 2014; 13(1): 20-5.

7. Lutfi MF. Acceptable alternatives for forced vital capacity in the spirometric diagnosis of bronchial asthma. Int J Appl Basic Med Res. 2011; 1(1): 20-3. doi: 10.4103/2229-516X.81975.

8. Li H, Liu C, Zhang $Y$, et al. The concave shape of the forced expiratory flow-volume curve in 3 seconds is a 
practical surrogate of FEV1/FVC for the diagnosis of airway limitation in inadequate spirometry. Respir Care. 2017; 62(3): 363-9. doi: $10.4187 /$ respcare.05016.

9. Raemdonck $\mathrm{K}$, Baker $\mathrm{K}$, Dale $\mathrm{N}$, et al. $\mathrm{CD}^{+}$and $\mathrm{CD} 8^{+} \mathrm{T}$ cells play a central role in a HDM driven model of allergic asthma. Respir Res. 2016; 17: 45. doi: 10.1186/s12931-016-0359-y.

10. Mannino DM, Higuchi K, Yu TC, et al. Economic burden of COPD in the presence of comorbidities. Chest. 2015; 148(1): 138-50. doi: 10.1378/chest.142434.

11. Cohen J, Postma DS, Vink-Klooster K, et al. FVC to slow inspiratory vital capacity ratio: a potential marker for small airways obstruction. Chest. 2007; 132(4): 1198-203. doi: 10.1378/chest.06-2763.

12. Siatkowska $H$, Jastrzebski $D$, Kozielski J. et al. [Smoking and clinical manifestation, lung function impairment, resulting comorbidities]. Pol Merkur Lekarski. 2010; 29(169): 8-13. Polish.

13. Kitaguchi $Y$, Komatsu $Y$, Fujimoto K, et al. Sputum eosinophilia can predict responsiveness to inhaled corticosteroid treatment in patients with overlap syndrome of COPD and asthma. Int J Chron Obstruct Pulmon Dis. 2012; 7: 283-9. doi: 10.2147/COPD.S30651.

14. Patel $A R$, Patel $A R$, Singh $S$, et al. Global initiative for chronic obstructive lung disease: The changes made. $\begin{array}{llll}\text { Cureus. } & \text { 2019; } & \text { 11(6): }\end{array}$ doi:10.7759/cureus.4985.

15. Albert P, Agusti A, Edwards L, et al. Bronchodilator responsiveness as a phenotypic characteristic of established chronic obstructive pulmonary disease. Thorax. 2012; 67(8): 701-8. doi: 10.1136/thoraxjnl2011-201458.

16. Quanjer PH, Ruppel GL, Langhammer A, et al. Bronchodilator response in FVC is larger and more relevant than in FEV1 in severe airflow obstruction. Chest. 2017; 151(5): 1088-98. doi: 10.1016/j.chest.2016.12.017.

17. Pan $M$, Zhang $H$, Sun $T$. Forced expiratory volumes in $3 \mathrm{~s}$ is a sensitive clinical measure for assessment of bronchodilator reversibility in elderly Chinese with severe lung function impairment. Int J Chron Obstruct Pulmon Dis. 2019; 14: 1803-11. doi: 10.2147/COPD.S197552.

18. Cazzola M, MacNee W, Martinez FJ, et al. Outcomes for COPD pharmacological trials: from lung function to biomarkers. Eur Respir J. 2008; 31(2): 416-69. doi: 10.1183/09031936.00099306.

19. Kainu A. Spirometric studies on the adult general population of Helsinki- bronchodilation responses, determinants, and intersession repeatability of FEV1, FEV6, FVC, and forced expiratory time. Doctoral dissertation. Department of Clinical Physiology and Research Unit of Respiratory Diseases, Department of Medicine Helsinki University Central Hospital Helsinki, Finland. 2008.

20. Ito JT, Lourenço JD, Righetti RF, et al. Extracellular matrix component remodeling in respiratory diseases: what has been found in clinical and experimental studies? Cells. 2019; 8(4): 342. doi: 10.3390/cells8040342.

21. Pellegrino R, Viegi G, Brusasco V, et al. Interpretative Strategies for Lung Function Tests. Eur Respir J. 2005; 26: 948-68. doi: 10.1183/09031936.05.00035205.

22. Allen $S$, Yeung $P$, Janczewski $M$, et al. Predicting inadequate spirometry technique and the use of FEV1/FEV3 as an alternative to FEV1/FVC for patients with mild cognitive impairment. Clin Respir J. 2008; 2(4): 208-13. doi: 10.1111/j.1752-699X.2008.00063.x.

23. Mehrparvar $A H$, Rahimian $M$, Mirmohammadi SJ, et al. Comparison of $\mathrm{FEV}(3), \mathrm{FEV}(6), \mathrm{FEV}(1) / \mathrm{FEV}(3)$ and $\mathrm{FEV}(1) / \mathrm{FEV}(6)$ with usual spirometric indices. Respirology. 2012; 17(3): 541-6. doi: 10.1111/j.14401843.2012.02146.x.

\section{Correspondence to Dr. Alaa Y. Jizar E-mail: mhy200145@gmail.com Received Jul. $2^{\text {nd }} 2020$ Accepted Oct. 20 2020}

